\title{
Development of an armored upper limb exoskeleton
}

\author{
Desarrollo de un exoesqueleto de armadura para miembro superior
}

\author{
Santiago López-Méndez (D) ${ }^{1 *}$, Hader Vladimir Martínez-Tejada (D) ${ }^{1}$, Marco Fidel Valencia-García (iD ${ }^{2}$ \\ ${ }^{1}$ Facultad de ingeniería mecánica, Universidad Pontificia Bolivariana. Circular 1a \#70-01 (Campus Laureles). C. P. 050030. Medellín, \\ Colombia. \\ ${ }^{2}$ Facultad de ingeniería mecánica, Universidad EIA. Km2 +200. Alto de Las Palmas. C. P. 055428. Envigado, Colombia.
}

\section{CITE THIS ARTICLE AS:}

S. López, H. V. Martínez and M.

F. Valencia. "Development of an armored upper limb exoskeleton", Revista Facultad de Ingeniería Universidad de Antioquia, no. 95, pp. 109-117, Apr-Jun 2020. [Online].

Available: https :

//www.doi.org/10.17533/

udea.redin. 20191148

\section{ARTICLE INFO:}

Received: March 12, 2019 Accepted: November 06, 2019 Available online: November 06, 2019

\section{KEYWORDS:}

Assistive robotics; wearable robots; robot kinematics; mechatronics

Robots de asistencia; robots usables; cinemática de robots; mecatrónica

\begin{abstract}
Personal safety is a critical aspect of daily life, but also in the military. Active soldiers often have to carry heavy gear during missions, which puts pressure on their backs. Therefore, the military must come up with new technologies that allow both protection and movement. In this paper, it is explaining the development of an armored upper limb exoskeleton with three degrees of freedom. To ensure portability, it is used battery-fed DC actuators. The system was encased in a metal matrix that doubles up as a protective plate. The exoskeleton, the control system, the actuators, and the plate are integrated so that they offer protection while supporting the flexion and extension of the upper limb.
\end{abstract}

RESUMEN: El aspecto de la seguridad personal resulta ser un tema de interés en la vida cotidiana y más aún en el aspecto militar; dada la exigencia física que se requiere para llevar equipamiento pesado, la industria militar desde hace algunas décadas se ha visto en la necesidad de desarrollar tecnologías que apoyen físicamente a los soldados sin perder la capacidad de proteger la integridad de la persona. En el presente artículo se aborda el diseño de un exoesqueleto de armadura para miembro superior con 3 grados de libertad. Se usa una metodología de diseño mecatrónico para ajustar tanto los requerimientos antropométricos y tecnológicos, para el sistema de actuación se emplean motores DC alimentados por batería para garantizar la portabilidad del dispositivo. Para soportar los sistemas mencionados se emplea un material de matriz metálica el cual a su vez tiene la función de proteger al usuario. La estructura del exoesqueleto propuesto, el sistema de control, los módulos de actuación y la armadura son integrados para generar un exoesqueleto portable para la protección y apoyo de los movimientos de flexo/extensión del miembro superior.

\section{Introduction}

Humans have always sought to develop tools to simplify tasks that require a lot of effort. Exoskeletons, one of these tools, act as a support mechanism that gives users enough strength to perform difficult tasks $[1,2]$, allows them to restore proper function of the limbs $[3,4]$, assist basic movements [5-8].

Over the past 50 years, the development of exoskeletons has been well documented. In the sixties, researchers at Cornell University developed a wearable mechanical

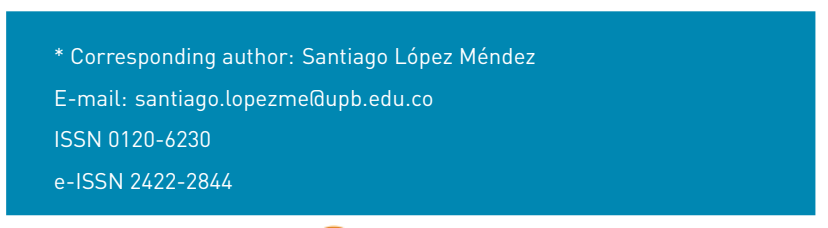

system with an approximate weight of $15.8 \mathrm{~kg}$ called "The Superman Suit" [9]. This system allowed the user to lift a weight of up to 1000 lbs. Meanwhile, researchers at G.E. developed a two-armed handling device to manipulate radioactive material [10]. Also, around that decade, researchers at Johns Hopkins University developed an upper limb exoskeleton that helped people with paralysis perform flexion of the elbow [11].

Although these developments are well-known and plenty, advances in the military are rather few and undisclosed [12]. Even so, some examples such as the Human Universal Load Carrier (HULC) [13] or the Raytheon XOS 2 [14], (which were designed as full-bodied suits) have gathered widespread attention. 
Now, exoskeletons must agree with the shape and functionality of the user's limbs. They should enhance the physical capabilities of the users and help them support loads that they would not be able to handle themselves. The goal is to bring human and machine closer so that there is a seamless integration of both [15]. In addition, the fabrication of new materials has brought forth a technological revolution whose outcome is the advancement of R+D+l [11]. Materials such as steel, alloys, and ceramics, are the focus, but advanced materials are also of interest [16].

In this project, it is developed a protoype of an armored exoskeleton that improves the strength of the upper limbs, while offering ballistic protection for personal safety purpose. This was done by reinforcing the metal matrix using carbon nanotubes. Given that in this paper our focus is the design and construction of the exoskeleton, it is suggested to any reader who might be interested in the fabrication process for the protective material, to look at the cited sources [17-20].

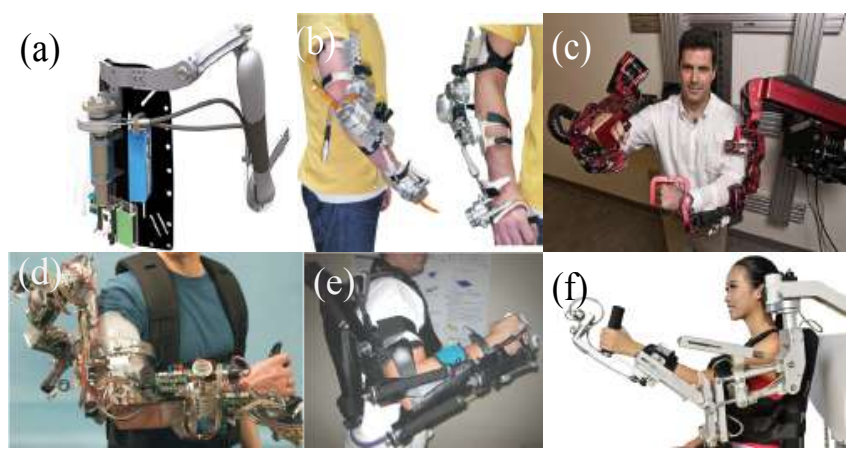

Figure 1 Interactive exoskeletons for the upper limb $[1,7,14-17]$

\section{State of art: wereable interactive system for the upper limb}

Since the sixties, projects in the industry, the military, and in healthcare have looked into the development of exoskeletons for the upper limb. Examples such as the "Titan Arm" Figure 1a, which uses electric actuators placed on the back lallowing power to be transferred toward the elbow via belts) are lightweight and practical, but lack a control system that accounts for voltage variations [1].

Other mechanisms such as the wearable orthosis for tremor assessment and suspension (WOTAS, Figure 1b) use a control system that is placed over the joint, but its overall construction is heavy, and it offers lower lifting capacity than other systems [8]. Also, the Robotic Upper
Extremity Repetitive Trainer (RUPERT, Figure 1e) uses pneumatic actuators that improve the strength-to-weight ratio, but the positioning system in these is inaccurate, which is an inconvenience during rehabilitation [21]. Mechanisms such as the EXO-UL7 (Figure 1c) and the NX-A2 (Figure 1f) are used during rehabilitation, but the weight and size of the actuators in these systems actually hinders their portability [22]. Also, there are full body exoskeletons such as [23].

Finally, mechanisms such as the Sensory Arm Master (SAM, Figure 1d) use complex control algorithms to execute haptic control actions, so that the mechanism can be used remotely; this is ideal in spacefaring missions [24].

\section{Desing of a linkage structure for the upper limb exoskeleton}

\subsection{Anatomy of the human arm}

The human arm has seven degrees of freedom (DOF): three on the shoulder, one on the elbow, and three on the wrist [25]; these enable the limb to move and reach objects in a certain space following a series of movements as shown in Figure 2 [24]. The greater the number of DOF in the exoskeleton, the better the support the user gets, but too many DOF can also lead to a complex structure and increase weight, which would make the system inefficient. Thus, in this research, it was decided to overlook the loads to the wrist and simply work with three actuators considering the linkage structure in [6]: two active DOF on the shoulder, and one active DOF on the elbow, as shown in Figure 3.

\subsection{Designing a structure for the exoskeleton}

The structure to allow flexion and extension of the joints is designed as shown in Figure 2 and thus, it mimics the natural movements of the limb. To support flexion/extension and abduction/adduction motions, three actuators (as already mentioned) are used and considered rotation (external and internal) as performed by a passive joint (that is, not performed by an actuator).

Figure 4 shows the initial design, in which actuators are placed over the joints, but after some research, there is settled for an actuator that was placed on the user's back and that transferred power to the joints using a belt and pulley system Figure 5. This design takes inspiration from the "Titan arm" Figure 1a, which integrates the structure with a shielded sheet; this design is modular, which makes the mechanism versatile. 

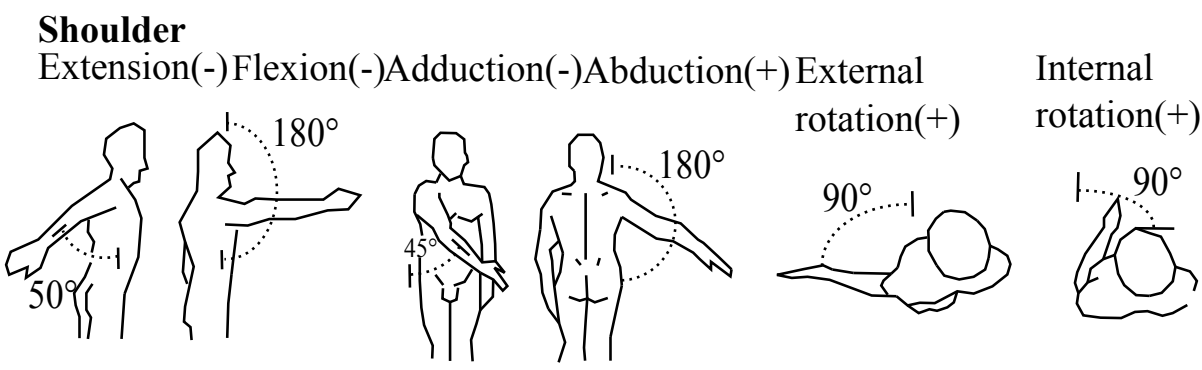

\section{Elbow}

Extension(-) Flexion(+)

Figure 2 DOFs of the human arm, motions of the wrist are overlooked. Taken and edited from [25]

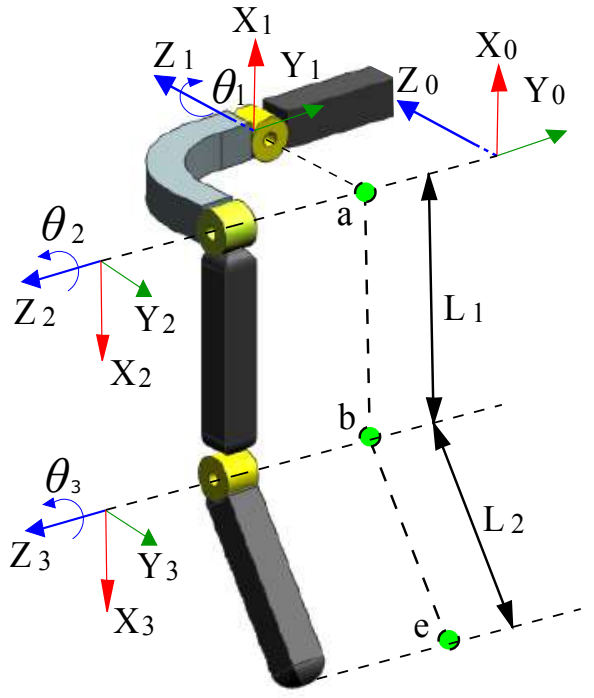

Figure 3 Kinematic configuration and coordinates of the 3-DOF exoskeleton

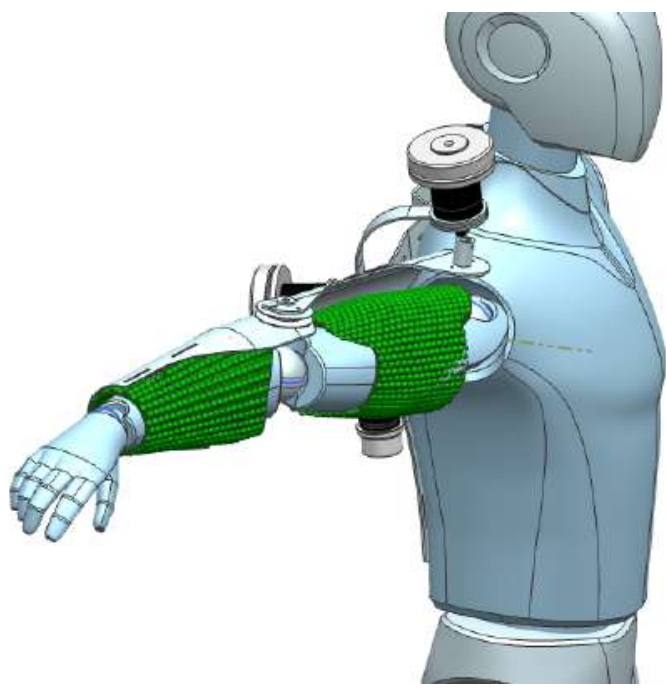

Figure 4 Initial design of the exoskeleton. Side view

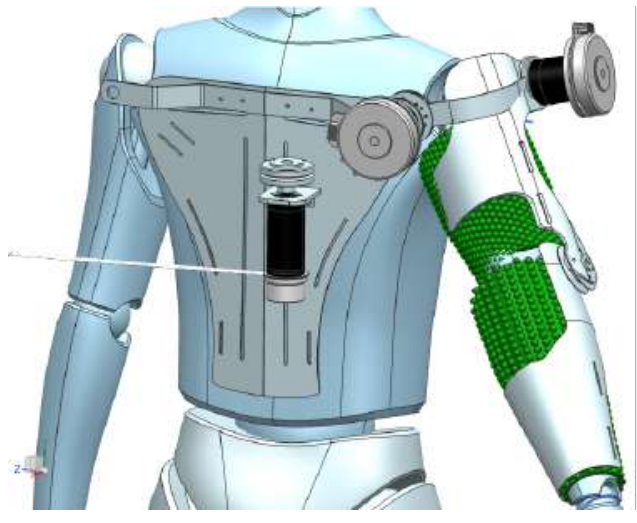

Figure 5 Basic design of the exoskeleton. Rear view

\subsection{Kinematic analysis of the proposed design}

Figure 6 a shows the robotic system that is divided into two components, so that it had a wider range of motion (ROM). A geometrical estimate of a potential healthy user yielded the dimensional values of the different sections and joints [6]. According to [6], it is possible to perform a kinematic study of the arm and motions of the joints using the data presented in Table 1 and Table 2 . Then, it is considered an initial geometrical model, as proposed by Hanavan, in which an estimate of the dimensions and angles of the joints was computed using simple geometry [25]; this model is shown in Figure 6.

To verify that the prototype covered all segments and mimicked the natural motions of a human arm, the exoskeleton was analyzed using forward and inverse kinematics, as described in [28].

\subsection{Forward kinematic analysis of the 3-DOF exoskeleton}

Forward kinematics defines the position and orientation of the wrist with respect to the base system as a function of joint variables. The position vector $p^{0}$ and the orientation vectors $n^{0}, s^{0}, a^{0}, p^{0}$ were obtained by computing the 


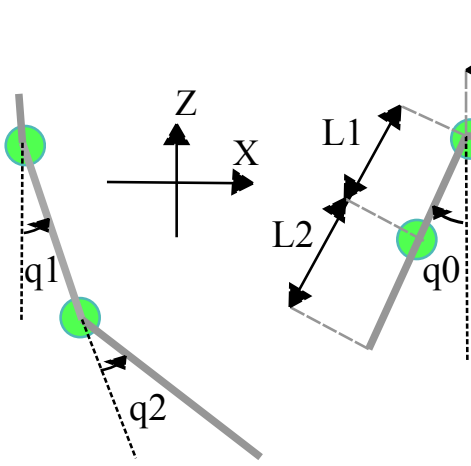

a)

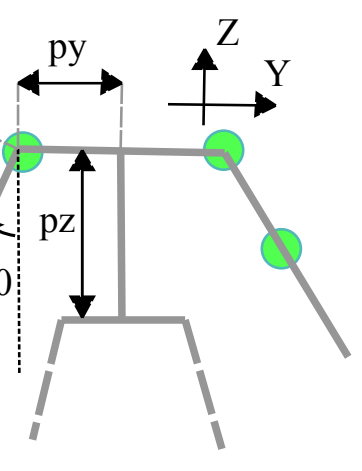

b)
Figure 6 a) Configuration of joints q1 (flexion/extension) and q2 (elbow). Side view. b) Configuration of joint q3 (abduction/adduction). Frontal view. Data on the components is shown in Table 1

Table 1 Mechanical specifications of an exoskeleton for the upper body. Taken and edited according to the measures of one author [26]

\begin{tabular}{lc}
\hline Segment & Length (mm) \\
\hline Hip - shoulder & 709.3 \\
Shoulder to shoulder (2py) & 420 \\
Wrist - Load & 25 \\
Shoulder - Elbow (L1) & 244.8 \\
Elbow - Wrist (L2) & 251.3 \\
Range of the shoulder & $-10^{\circ} \sim 115^{\circ}$ \\
lq0 and q1) & $5^{\circ} \sim 120^{\circ}$ \\
Range of the elbow (q2) & \\
\hline $\begin{array}{l}\text { Note: Measures in Table 1 are taken with the upper arm abducted } 90^{\circ} \text {, in this } \\
\text { position the acromial is marked closer to the radial compared to the standard } \\
\text { position. }\end{array}$
\end{tabular}

Table 2 Mass of body segments as \% of total body mass [27]

\begin{tabular}{lc}
\hline Segment of the body & \% of total body mass \\
\hline Upper Arms & 5.31 \\
Forearms & 3.64 \\
Hands & 1.41 \\
\hline
\end{tabular}

transformation matrix as shown in Equation 1.

$$
{ }_{3}^{0} \mathrm{~T}={ }_{1}^{0} \mathrm{~T}_{2}^{1} \mathrm{~T}_{3}^{2} \mathrm{~T}=\left(\begin{array}{cccc}
\mathbf{n}^{0} & \mathbf{s}^{0} & \mathbf{a}^{0} & \mathbf{p}^{0} \\
\mathbf{0} & \mathbf{0} & \mathbf{0} & \mathbf{1}
\end{array}\right)
$$

Where $\theta=\left(\theta_{1} \theta_{2} \theta_{3}\right)$ indicates the angles of each joint, and ${ }_{i-1}^{i} \mathrm{~T}$ represents the transformation matrix from joint $i$ to joint $i-1$ The definition of the coordinate systems of the joints (shown in Table 3) follow the Denavit-Hartenberg (D-H) convention.

For the forward analysis, the $\mathrm{D}-\mathrm{H}$ parameters are used, where 0 corresponds to the initial coordinate, there is considered for the analysis that the coordinate systems 0,1 and 2 have the same origin and is in point $a$ (Figure 3),
Table 3 D-H parameters of the 3-DOF exoskeleton

\begin{tabular}{lllll}
\hline Linkage & $\boldsymbol{\alpha}_{\boldsymbol{i}}-\mathbf{1}$ & $a_{i-1}$ & $\boldsymbol{\theta}_{\boldsymbol{i}}$ & $d_{\mathrm{i}}$ \\
\hline 1 & 90 & 0 & $\boldsymbol{\theta}_{\mathbf{1}}$ & 0 \\
2 & 0 & 0 & $\boldsymbol{\theta}_{\mathbf{2}}$ & 0 \\
3 & 0 & 0 & $\boldsymbol{\theta}_{\mathbf{3}}$ & $L_{1}$ \\
\hline
\end{tabular}

and system 3 is on point $b$. D-H parameters are shown in Table 2. The coordinates of the final effector with respect to the fixed system ${ }^{0} P_{e}$ can be computed as ${ }^{0} P_{e}={ }_{3}^{0} T^{b} P_{e}$ where ${ }^{b} P_{e}=\left(L_{2} 00\right)^{T}$.After the analysis, it is obtained the exoskeleton's workspace (shown in Figure 7). The lateral view of that workspace is shown in Figure 8 . In this view, the $(0,0,0)$ point of the system sits right above the center of the shoulder. 5000 points were used to build this image; the outcome is a true representation of the relative movement of the right upper limb.

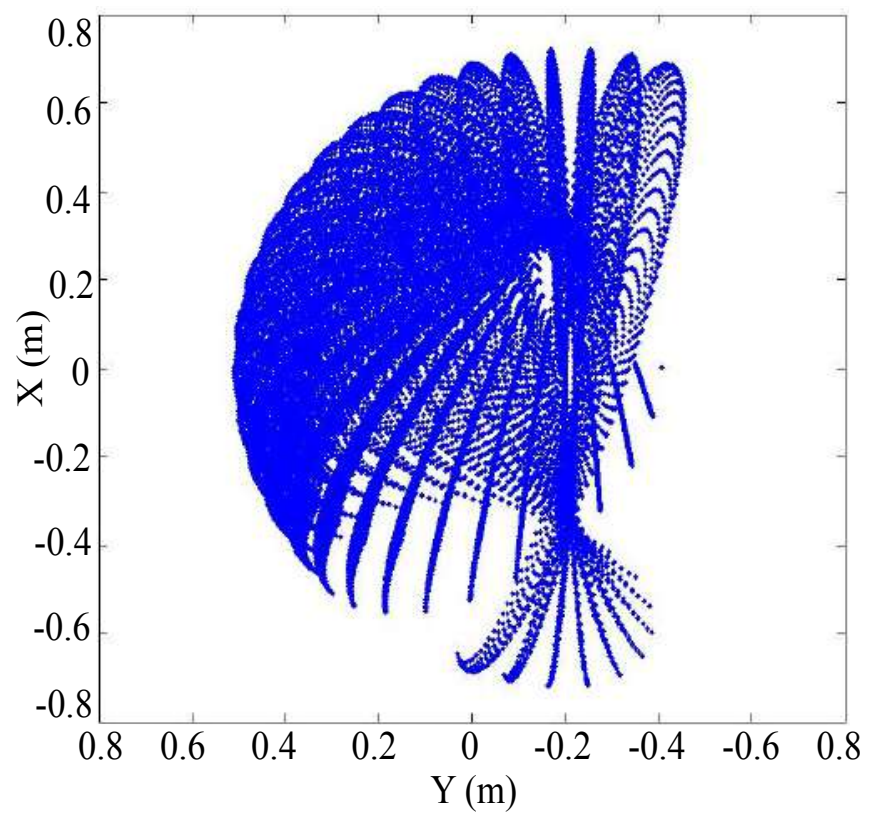

Figure 7 Upper view of the workspace (mm)

\section{Choosing the actuator module}

To ensure the portability of the exoskeleton, electric, D-C actuators are used. To determine the necessary torque they had to put out for move the link an angle of $\theta$, a balanced of torques around the pivotal point for each joint is made. To do that, it is considered "the worst possible scenario". That is, when the distance at which vector $F$ is positioned generates the maximum torque $T$ around de pivot point, which is calculated as indicated in Equation 2.

$$
\sum T=m g L-T=0
$$




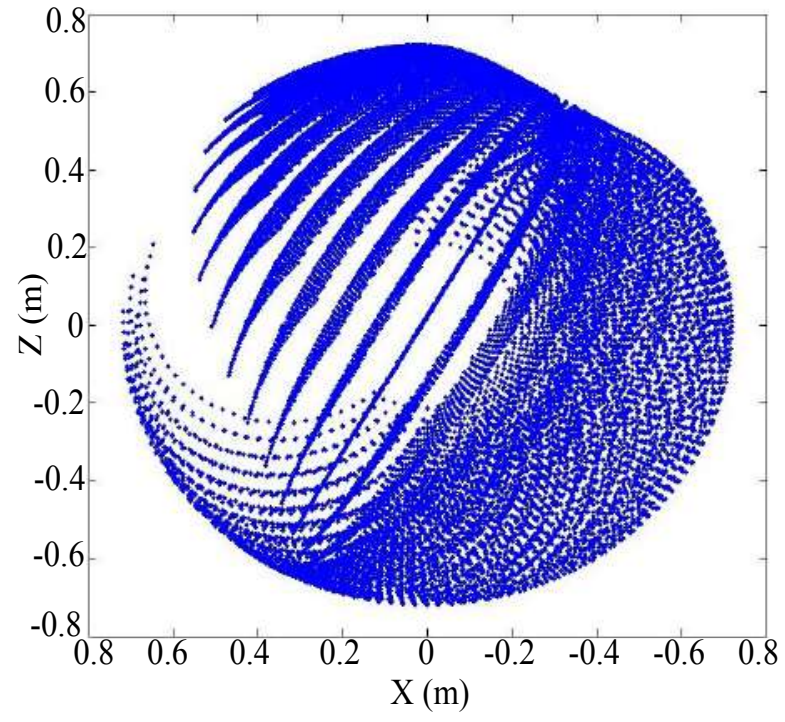

Figure 8 Side view of the workspace $(\mathrm{mm})$

where $m$ is the mass of the link, $g$ is the gravity acceleration, and $L$ is the distance that maximize the torque around the joint, the maximum torque was obtained when the component was positioned perpendicular to the vector of gravity force $(F)$. As shown in Figure 9.
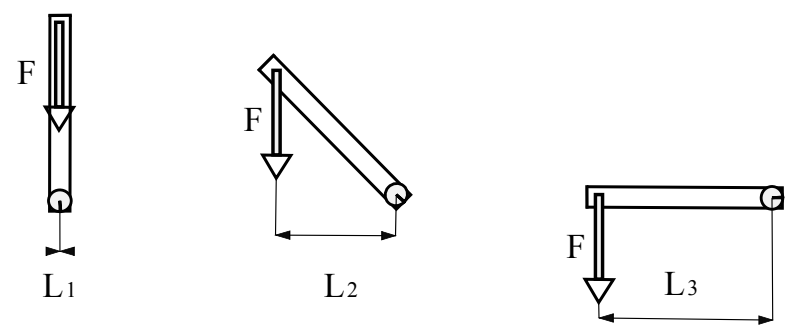

Figure 9 Variation of the effective distance produced by the torque with respect to the position of the component

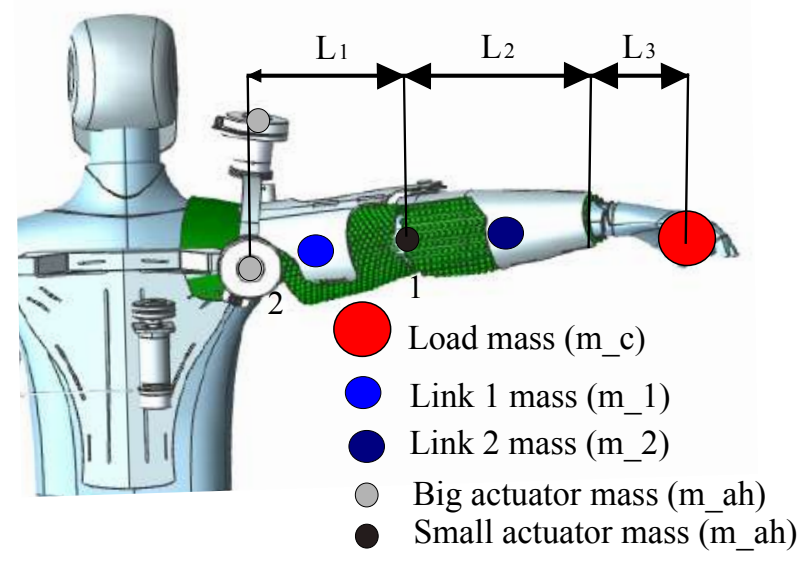

Figure 10 Loads on the exoskeleton

For the first actuator, the required torque was computed from the object's weight (Figure 10) times the distance to the pivot. In addition, the total mass of the component was defined as the approximate weight of the exoskeleton in this section labout $2 \mathrm{Kg}$ ). It is assumed that the center of mass was positioned right at the center of section $L_{2}$. Then, it is built a free body diagram (Figure 11) and computed the torque each motor put out so that the equilibrium be maintained, by Equations 3 and 4 .

$$
\begin{gathered}
\tau_{3}=\left(L_{2}+L_{3}\right) W_{c}+\frac{1}{2} L_{2} W_{2} \\
\tau_{1,2}=\left(L_{1}+L_{2}+L_{3}\right) \begin{array}{l}
W_{c}+\left(\frac{1}{2} L_{2}+L_{1}\right) W_{1}+L_{1} W_{A s}+ \\
\frac{1}{2} L_{1} W_{1}
\end{array}
\end{gathered}
$$

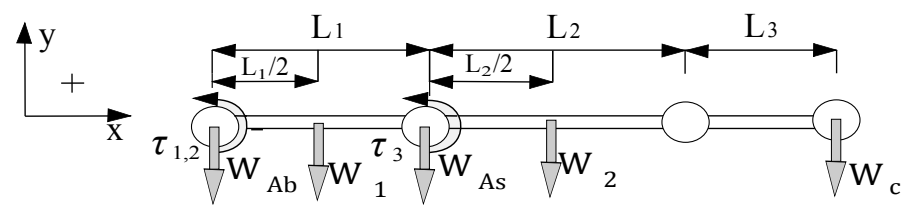

Figure 11 Free body diagram of one link exoskeleton

The equations presented account only for the static forces. That is, when the exoskeleton's arm is positioned horizontally. But this is not necessarily the "worst possible case". For the arm to be able to move from a resting position, it requires acceleration. To solve the equation that takes into consideration this additional torque, we consider the rotational kinematics following the Equation 5.

$$
\sum \tau_{p}=I \alpha
$$

In the case of an arm, the moment of inertia is taken into consideration by rotating the arm with respect to the pivot at the tail end. Thus, the moment of inertia can be computed as indicated in Equation 6

$$
I=\frac{m r^{2}}{2}+m r^{2}
$$

For every joint, the moment of inertia must be computed as the sum of the products of all masses times the square of the distance to the pivot $(r)$ as the Equation 7. The mass of the actuator cannot be considered then, as it does not generate any torque with respect to its axis. In this way, $r$ represents the distance from the center of mass to the pivot.

$$
I_{N}=\sum_{i=1}^{N-1} \frac{m_{i} r^{2}}{2}
$$

Given that the moment of inertia varies considerably from one component to the other, the angular acceleration is another factor that cannot be considered. According to [29], the maximum and minimal angular velocities $(\omega)$ 
a)

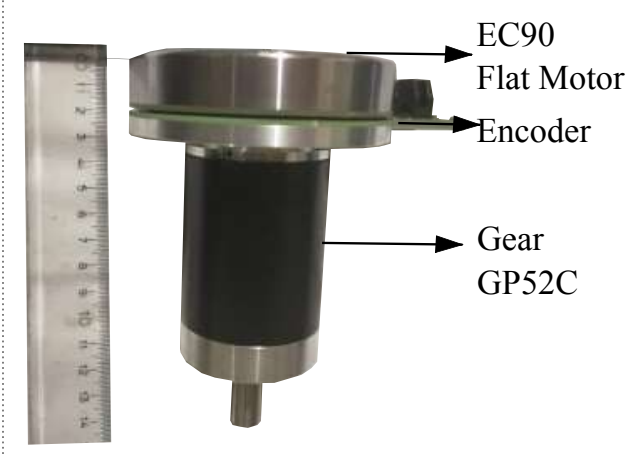

b)

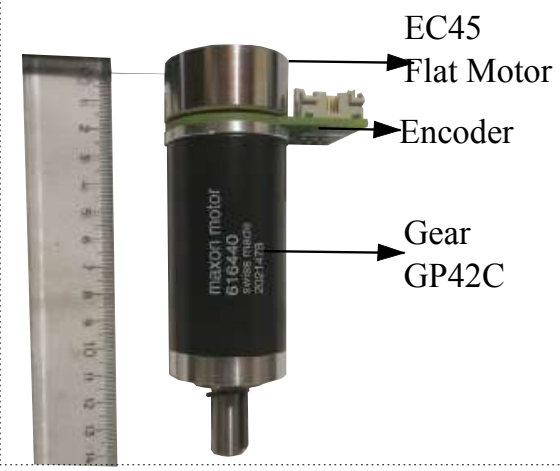

Figure 12 Actuators (Maxon). Left: shoulder joint, Right: elbow joint

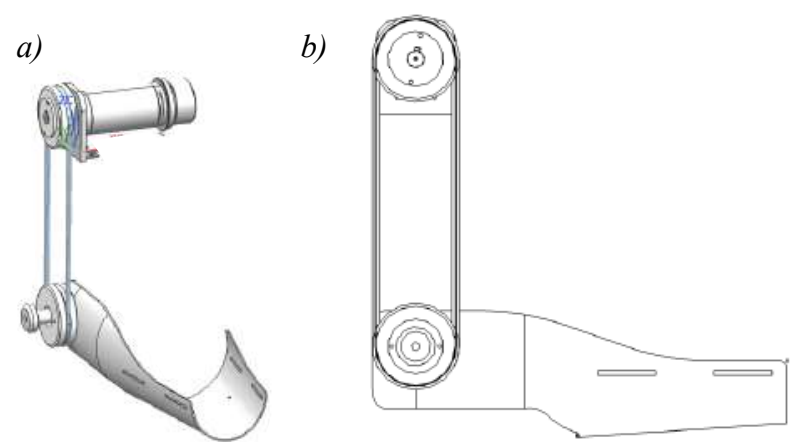

Figure 13 Pulley System a) Isometric b) Side view

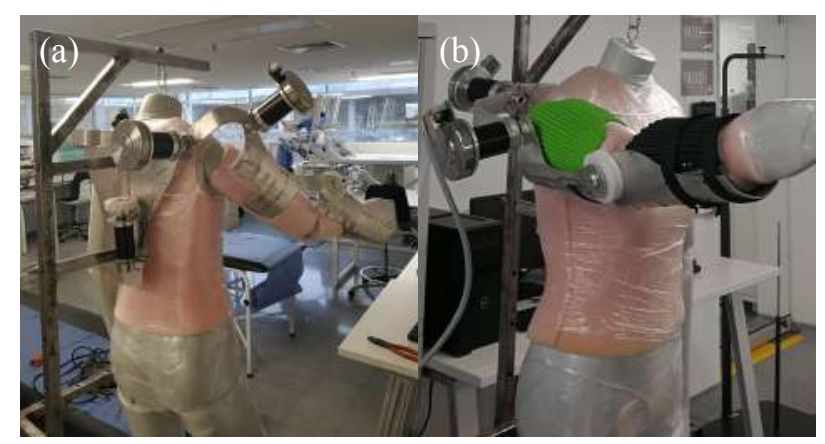

Figure 14 Prototype of the exoskeleton a) Rear view b) Side view

reached by the shoulder during a daily activity was 171.5 $\mathrm{deg} / \mathrm{s}$ and $16.2 \mathrm{deg} / \mathrm{s}$ and for de elbow were $172.8 \mathrm{deg} / \mathrm{s}$ and $35 \mathrm{deg} / \mathrm{s}$. Nevertheless the power requirements for high $\omega$ demanded in few movements do not worth the reduction in torque. For the exoskeleton purpose in this project, where high torque is required, it is decided to stablish the maximum angular velocities for all joints in an average value of $90 \%$. Then, the angular acceleration $\alpha$ can be computed using Equation 8.

$$
\theta=\frac{1}{2} \alpha t^{2}
$$

Where $\theta$ is the angle traveled by the joint in a time $t$, solving for $\alpha$ provides $\alpha=3.14 \frac{\mathrm{rad}}{\mathrm{s}^{2}}$.

The torque that is necessary to move the arm from a resting position is calculated using the relation shown in Equation 9.

$$
\sum \tau_{N}=F S\left(\tau_{N}(\text { Static })+\tau_{N}(\text { Dynamic })\right)
$$

By replacing the values shown in Table 1 and Table 2 for a healthy user with a mass of $80 \mathrm{Kg}$ and considering a factor of safety $(F S)$ equal to 1.1 in Equation 9 then get Equation 10.

$$
\begin{aligned}
& \tau_{1,2}(\text { Static })=31.58 \mathrm{~N} \cdot \mathrm{m} \\
& \tau_{1,2}(\text { Dynamic })=1.07 \mathrm{~N} \cdot \mathrm{m} \\
& \tau_{3}(\text { Static })=9.23 \mathrm{~N} \cdot \mathrm{m} \\
& \tau_{3}(\text { Dynamic })=0.30 \mathrm{~N} \cdot \mathrm{m}
\end{aligned}
$$

$\tau_{1,2}=35.92 \mathrm{~N} \cdot \mathrm{m}$ minimum torque required by the actuator at the shoulder.

$\tau_{3}=10.49 \mathrm{~N} \cdot \mathrm{m}$ minimum torque required by the actuator at the elbow.

There were selected two references of Maxon Motor as electric DC actuator showed in Figure 12. On the left there is a Maxon EC90Flat actuator, which was selected for the shoulder actuator, whose nominal torque $\tau_{b n}=444 \mathrm{mN} \cdot \mathrm{m}$ and Maxon's GP52C reference reducer has an absolute reduction ratio of $2197 / 27$ which gives as a result a torque after the reduction of $\tau_{2 m}=36.13 \mathrm{~N} \cdot \mathrm{m}$. On the right there is a Maxon EC45Flat actuator selected for the elbow actuator, its nominal torque: $\tau_{s n}=128 \mathrm{mN} \cdot \mathrm{m}$ and Maxon's GP42C reference reducer has an absolute reduction ratio of $2401 / 16$, performing the torque calculation with the reduction ratio is that $\tau_{b m}=19.21 \mathrm{~N} \cdot \mathrm{m}$. The torques of the selected actuators $\tau_{b m}$ and $\tau_{s m}$ meet the requirements of Equation 9, since $\tau_{b m} \geq \tau_{1,2}$ and $\tau_{s m} \geq \tau_{3}$. 


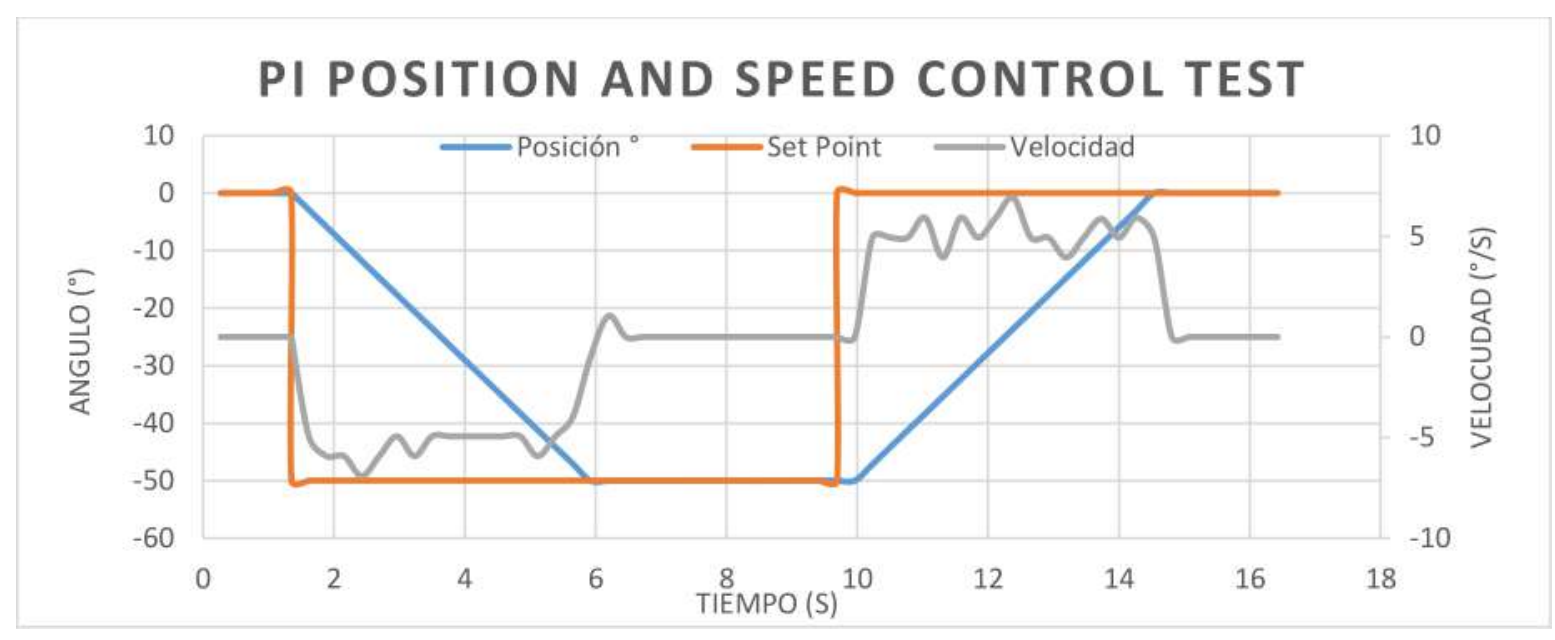

Figure 15 Position and speed control test

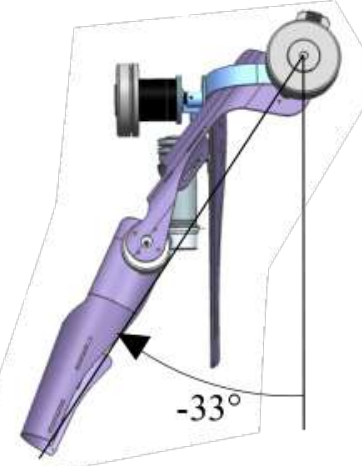

Shoulder Extension

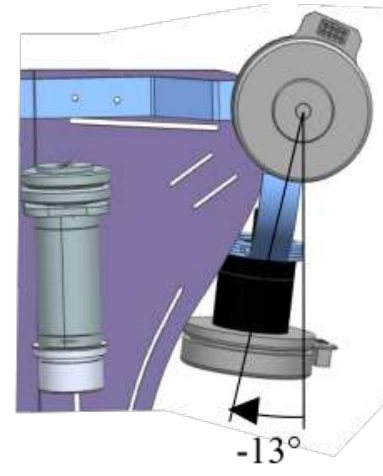

Shoulder Adduction

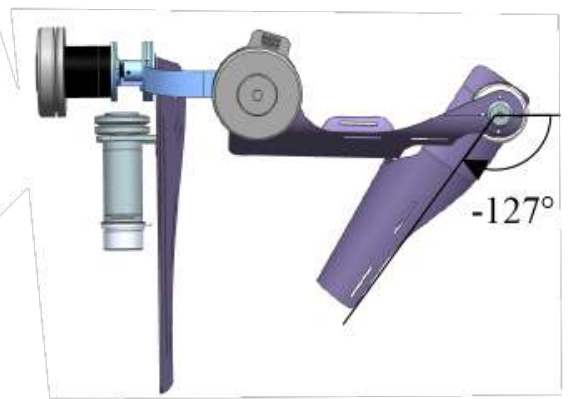

Elbow Extension

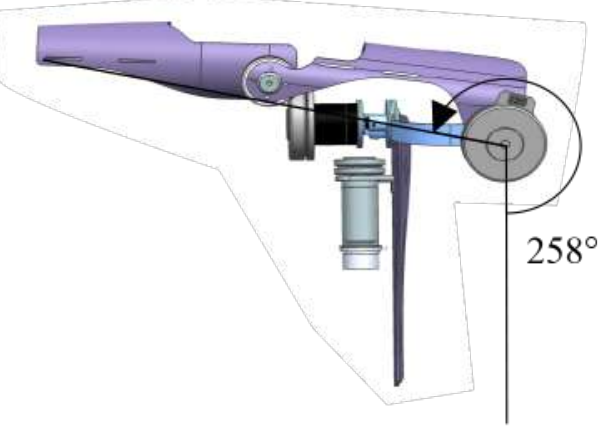

Shoulder Flexion

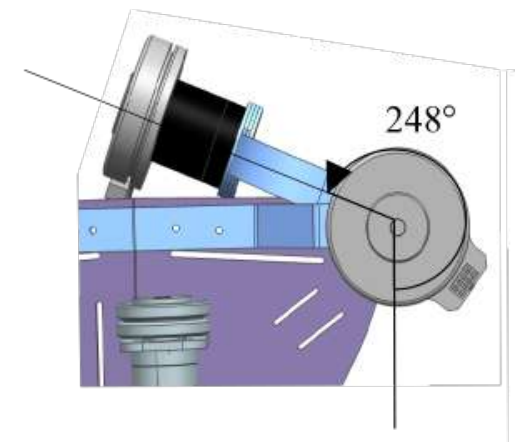

Shoulder Abduction

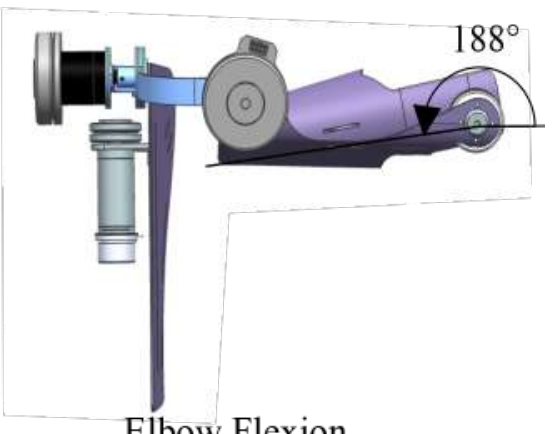

Elbow Flexion

Figure 16 Control Test - ROM Exoskeleton

\section{System assembly}

The exoskeleton and the actuator control system were integrated as shown in Figure 4 and Figure 5 . shows finished assembly for the structure. The system was fitted on an articulated mannequin, and then fixed on a steel structure for protection. The power transferred to each joint was supplied by a different actuator: For the elbow, the actuator was placed on the back and then power was transferred via a belt and pulley system (Figure 13); for the shoulder, the actuator was placed directly over the joint. All the pieces of the control system were placed on 
the back, (including batteries) but it is decided to used a DC power supply VRLA batteries and left the integration with ion lithium batteries for future advances. shows the assembly with the concept armor 3D printed with the exoskeleton. The assembled prototype is shown in Figure 14.

\section{Control system and hardware validation}

For hardware validation, a PI position control is sintonized using the EPOS4 Compact controller from Maxon Motors. With this control system, it is possible to control position and speed. In the performed test, there the maximum speed is $7.2^{\circ} / \mathrm{s}(0.125 \mathrm{rad} / \mathrm{s})$ where the set point speed is around $6^{\circ} / \mathrm{s}(0.1 \mathrm{rad} / \mathrm{s})$. The constant slope that can be observed in Figure 15 indicates that the maximum speed is fixed and this can be modified by the user at any time. Next, the ROM that allows the built robotic system is verified, the limits in the ROM shown are given by physical factors and interference between the pieces. The articular ROM for each of the active joints in the EPMSD is shown in Figure 16 . Table 4 summarizes the results presented in the exoskeleton ROM. When comparing the ROM with the data in Table 1, it can be concluded that the exoskeleton has a suitable ROM for use by a human being. However, for safety, the electronic and control system must take into account the gap between the limits of joint movements between the user and the robotic system.

Table 4 Control Test - ROM Exoskeleton

\begin{tabular}{llll}
\hline & Shoulder & & Elbow \\
\hline & Abduction - & Flexion - & Flexion - \\
& Abduction & Extension & Extension \\
\hline Joint range & $-13^{\circ}-248^{\circ}$ & $33^{\circ}-258^{\circ}$ & $-127^{\circ}-188^{\circ}$ \\
\hline
\end{tabular}

\section{Conclusions and future perspectives}

The structure of the exoskeleton takes inspiration from the geometry of the human body, mainly the right arm, and takes into consideration the DOFs and ROM, which were found using the kinematic analysis.

The actuator module consists of a DC motor that transfers power to the elbow via a belt and pulley system. Meanwhile, two actuators placed over the shoulder allow flexion/extension and abduction/adduction motions. To determine the torque required from each actuator, it is performed an analysis of the static and dynamic forces that affected each joint. In the future, it is expected to implement different strategies of adaptive control to have a say on the strength and positioning of the system.

There is also expected to be able to integrate impedance control into the control system, and to develop accesories that provide additional DOFs, such as in the development of systems for the lower limb. In addition, it is expected to integrate the shielding material via compo forging of aluminum and carbon nanotubes (Al/CNTs), so that we may be able to carry out performance tests in a lab setting.

\section{Acknowledgments}

We, the authors, would like to extend our acknowledgments to Colciencias, UPB University, and EIA University for their support of this project: "Fabricación de nanomateriales para aplicación en exoesqueletos de protección, vía Compoforjado (c) de aluminio reforzado con nanotubos de carbono (Al/CNTS)-CNT Kinetics".

\section{References}

[1] The Titan Arm, ASTM Standardization News, 2013.

[2] E. Yagi, D. Harada, and M. Kobayashi, "Upper-limb power-assist control for agriculture load lifting," Int. J. Autom. Technol, vol. 3, no. 6, 2009. [Online]. Available: https://doi.org/10.20965/ijat.2009. p0716

[3] H. Kawasaki and et al, "Hand motion assist robot for rehabilitation therapy," J. Robot. Mechatronics, vol. 26, no. 1, pp. 103-104, Feb. 2014.

[4] T. Ando and et al, "Myoelectric-controlled exoskeletal elbow robot to suppress essential tremor: Extraction of elbow flexion movement using STFTs and TDNN," J. Robot. Mechatronics, vol. 24, no. 1, february 2012. [Online]. Available: https://doi.org/10.20965/jrm. 2012.p0141

[5] L. Xiangpan, “Design of wearable wearable wearable wearable power assist wear for low back support support support support using pneumatic pneumatic pneumatic pneumatic actuators," Ph.D thesis, Okayama University, Okayama, Japan, 2013.

[6] X. Wang, Q. Song, X. Wang, and P. Liu, "Kinematics and dynamics analysis of a 3-DOF upper-limb exoskeleton with an internally rotated elbow joint," Appl. Sci., vol. 8, pp. 1-19, Mar. 2018.

[7] M. H. Rahman, M. Saad, J. P. Kenné, P. S. Archambault, and T. K. Ouimet, "Development of a $4 \mathrm{DoFs}$ exoskeleton robot for passive arm movement assistance," Int. J. Mechatronics Autom, vol. 2, no. 1, January 2012. [Online]. Available: https://doi.org/10.1504/ IJMA.2012.046587

[8] Y. Matsumoto and et al, "Development of an exoskeleton to support eating movements in patients with essential tremor," J. Robot. Mechatronics, vol. 25, no. 6, pp. 949-958, Dec. 2013.

[9] J. L. Pons, Wearable Robots: Biomechatronic Exoskeletons. Madrid, España: John Wiley \& Sons, 2008.

[10] K. Anam and A. A. Al-Jumaily, "Active exoskeleton control systems: State of the art," Procedia Eng., vol. 41, 2012. [Online]. Available: https://doi.org/10.1016/j.proeng.2012.07.273

[11] I. G. Crouch, "Introduction to armour materials," in The Science of Armour Materials, I. G. Crouch, Ed. United Kingdom: Elsevier, 2016, pp. 1-54.

[12] C. M. Wenig, C. O. Schmidt, T. Kohlmann, and B. Schweikert, "Costs of back pain in germany," Eur. J. Pain, vol. 13, no. 3, March 2009. [Online]. Available: https://doi.org/10.1016/j.ejpain.2008.04.005 
[13] (2015) From HULC to MANTIS to FORTIS exoskeleton: Development history. Exoskeleton. Accessed May. 09, 2017. [Online]. Available: https://bit.ly/33LL1FP

[14] xos 2. Exoskeleton. Accessed May. 02, 2017. [Online]. Available: https://rtn.co/2OzHv6G

[15] Raytheon XOS 2 exoskeleton, second-generation robotics suit. Army-Technology. Accessed Nov. 27, 2017. [Online]. Available: https://bit.ly/2oyu60r

[16] V. Sanchéz and M. J. Sánchez, Materiales para la Defensa, 1st ed. Madrid, España: VA. Impresores, 2012.

[17] H. Vladimir and M. F. Valencia, "Semisolid processing of Al/B-SiC composites by mechanical stirring casting and high pressure die casting," in Recent Researches in Metallurgical Engineering - From Extraction to Forming, G. Ahuett and A. Arrambide, Eds. Intech Open Science, 2012, pp. 125-142.

[18] M. F. Valencia, "Procesamiento semisólido de compuestos $\mathrm{Al} / \mathrm{SiC}$ por agitación mecánica, para elaborar componentes compoforjados," M.S. thesis, Universidad Pontificia Bolivariana, Medellín, Colombia, 2011

[19] W. Chen and et al, "Multi-scale experiments on soft body armors under projectile normal impact," Int. J. Impact Eng., vol. 108, October 2017. [Online]. Available: https://doi.org/10.1016/j.ijimpeng.2017. 04.018

[20] H. V. Martínez and et al, "One-step SSM process by MSC \& HPDC for metallic components," Solid State Phenom., vol. 141, January 2008. [Online]. Available: https://doi.org/10.4028/www.scientific.net/SSP. $141-143.103$

[21] S. Balasubramanian and et al, "RUPERT: An exoskeleton robot for assisting rehabilitation of arm functions," in Virtual Rehabilitation, Vancouver, BC, Canada, 2008, pp. 163-167.

[22] W. Yu, J. Rosen, and X. Li, "PID admittance control for an upper limb exoskeleton," in American Control Conference, San Francisco, CA, USA, 2011, pp. 1124-1129.

[23] M. Ishii, K. Yamamoto, and K. Hyodo, "Stand-alone wearable power assist suit -development and availability-," J. Robot. Mechatronics, vol. 17, no. 5, March 2006. [Online]. Available: https://doi.org/10. 1299/kikaic.72.857

[24] P. Letier, "Bras exosquelette haptique conception et contrôle laboratoire des structures actives," PhD dissertation, Université Libre de Bruxelles, Bruxelles, Belgium, 2010.

[25] M. Couvertier, T. Monnet, and P. Lacouture, "Identification of human body segment inertial parameters," in $22^{\text {nd }}$ Congr. Eur. Soc. Biomech., Lyon, France, 2016.

[26] B. Ugurlu, M. Nishimura, K. Hyodo, M. Kawanishi, and T. Narikiyo, "Proof of concept for robot-aided upper limb rehabilitation using disturbance observers," IEEE Trans. Human-Machine Syst., vol. 45, no. 1, pp. 110-118, Feb. 2015

[27] J. Clerval, R. Lacombe, M. Adolphe, B. Zagrodny, and Z. Kirchof, "Center of mass of human's body segments," Mech. Mech. Eng, vol. 21, no. 3, pp. 485-497, 2017.

[28] A. Barrientos, C. Balaguer, L. F. Peñin, and R. Aracil, Fundamentos de Robótica, 2nd ed. Aravaca, Madrid: McGraw-Hill, 2007.

[29] J. Rosen, J. C. Perry, N. Manning, S. Burns, and B. Hannaford, "The human arm kinematics and dynamics during daily activities - toward a 7 DOF upper limb powered exoskeleton," in $12^{\text {th }}$ International Conference on Advanced Robotics, Seattle, WA, USA, 2005. 